\title{
Research in the North American North: Action and Reaction
}

\author{
FAE L. KORSMO ${ }^{1}$ and AMANDA GRAHAM ${ }^{2}$
}

(Received 11 September 2000; accepted in revised form 19 November 2001)

\begin{abstract}
The political mobilization of indigenous peoples in the North American North has resulted in new guidelines, statements of ethical principles, and consultative processes for the conduct of scientific research. This article explores the history of large-scale physical science in the North, the development of ethical principles for research conduct in Canada and the United States, and the potential difficulties of bridging the gaps between scientists and indigenous communities.
\end{abstract}

Key words: research conduct, participatory research, community consultation, research ethics, history of science, social studies of science, ethical practice, Canada, Alaska

RÉSUMÉ. La mobilisation politique des populations autochtones de l'Amérique du Nord septentrionale a débouché sur de nouvelles lignes directrices et déclarations de principes de déontologie ainsi que sur des processus consultatifs novateurs visant la conduite de la recherche scientifique. Cet article examine l'histoire de la science physique menée sur une grande échelle dans le Nord, l'élaboration de principes de déontologie concernant la recherche au Canada et aux États-Unis, ainsi que les difficultés qu'il peut y avoir à rapprocher les scientifiques et les collectivités autochtones.

Mots clés: poursuite de la recherche, recherche participative, consultation des collectivités, éthique de la recherche, histoire des sciences, études sociologiques des sciences, code déontologique, Canada, Alaska

Traduit pour la revue Arctic par Nésida Loyer.

\section{INTRODUCTION}

The term "research" carries different contextual meanings in the different scientific and humanistic disciplines, depending on what their members see as legitimate or appropriate questions, methods, analytic tools, and settings (e.g., field or laboratory). However varied the fields of study, from chemical oceanography to art history, the research enterprise-and the communication of the research through teaching-constitutes the core of each discipline. Independent research done well indicates the maturation of the scholar and certifies his or her membership in a disciplinary community.

In northern North America, indigenous groups have not always seen the positive aspects of research. From an indigenous perspective, southern researchers came north, did "fieldwork" in the summer, and returned home to analyze and write up their results as the acknowledged "experts" on northern studies (Flaherty, 1995). Some Native people saw the researchers as taking valuable information from their communities while ignoring community perspectives and needs (Tizya, 1975). On the other hand, indigenous groups were faced with their own research challenges when they mobilized politically and presented land claims throughout the 1970s and 1980s. The quantity of research required to support Native claims to the land was staggering. As Senkpiel and Easton (1988:10) noted, indigenous residents were "responsible for what may be the largest research enterprise in Canada's North: the attempt to document as fully as possible all aspects of traditional life." The indigenous groups were not disciplinary communities, but rather linguistic, cultural, geographic, and political communities hoping to use research to attain a degree of autonomy. Consequently, and over time, anthropologists, historians, and other social science researchers forged ties with indigenous communities to document historical and cultural connections to land and water. However, these collaborations rarely extended beyond the social sciences. The goals of physical science research often seemed far removed from the interests of northern residents. Only recently have the natural (or biological) and physical sciences become involved in research programs in which indigenous individuals or organizations participate in setting priorities, evaluating proposals, and making decisions on grants (Watt-Cloutier, 2000). It remains to be seen how well these collaborations are serving the interests of the scientists and the communities. It is clear, however, that for the non-social sciences, the direct involvement of local indigenous communities in decision-making is a major change in northern research.

\footnotetext{
${ }^{1}$ Office of Polar Programs, National Science Foundation, Suite 755, 4201 Wilson Boulevard, Arlington, Virginia 22230, U.S.A.; present address: Experimental Program to Stimulate Competitive Research (EPSCoR), National Science Foundation, Suite 875, 4201 Wilson Boulevard, Arlington, Virginia 22230, U.S.A.; fkorsmo@nsf.gov

${ }^{2}$ Yukon College, The Northern Review, Box 2799, Whitehorse, Yukon Y1A 5K4, Canada

(C) The Arctic Institute of North America
} 
This paper traces the development of ethical principles and guidelines for the conduct of research, with a focus on natural and physical science research, in the Arctic and Subarctic of North America. The consensus of the nonsocial scientists seemed to be that these ethical principles and guidelines applied mainly to the social scientists who had extensive contact with human beings. However, it has become apparent that the natural and physical sciences could also have enormous impacts on policies, regulations, and other crucial aspects of northern life.

This paper concerns the relationship between the natural and physical science communities, on the one hand, and northern indigenous communities, on the other. It is not a research paper, but is intended to give an informative background and raise questions for further discussion.

\section{FROM POLAR YEARS TO SHEBA: THE ARCTIC AS A NATURAL LABORATORY}

Explorers have studied and mapped the northern reaches of the globe for centuries. However, exploration, with its emphasis on discovery of new lands and seas and difficult one-time (and sometimes one-way) voyages, began to give way to a more systematic science, with regular and meticulous observations, in the latter half of the 19th century. One scientific traveler, Alexander von Humboldt (17691859), encouraged worldwide studies of natural phenomena through the collection of data by standardized means (Zeller, 1996). Similarly, Karl Weyprecht, a lieutenant in the Austro-Hungarian Navy and leader of the AustroHungarian North Pole Expedition of 1872-74, returned from his exhausting expedition to the Arctic Ocean to argue that, instead of geographic exploration, polar research needed systematic, coordinated observations over the period of a year (Gerson, 1958; Barr, 1983; Levere, 1993). Weyprecht's suggestion of a series of coordinated, synchronous expeditions distributed over the various Arctic regions became the basis of the first International Polar Year (IPY) of 1882-83 (Chapman, 1960; Currie, 1987). During the first IPY, synchronized observations of geomagnetism, aurora, and meteorology were carried out at a dozen different stations sprinkled throughout the Arctic and two stations in the Antarctic (Barr, 1983). By the time of the second IPY in 1932-33, weather balloons carrying self-recording instruments extended the observations into the atmosphere (Chapman, 1960). Finally, the International Geophysical Year (IGY) of 1957-58 extended the synchronous observations deep into the ocean and into the ionosphere (Sullivan, 1961). The use of precision and control afforded by standardized measures to obtain a picture of the earth as a total system motivated the scientific organizers of the IGY (Gerson, 1958).

From the first International Polar Year to the present, the Arctic has been seen as a "natural laboratory" (e.g., United States Arctic Research Plan, 1997). The area features continuous paleoclimate records buried in the ice, exhibits dramatic effects of global warming, and offers scientists a chance to visit and study seldom-seen corners of the earth. Indeed, the notion of a sparsely populated wilderness where science could be carried out with a minimum of interference made the isolation of the Arctic particularly attractive. The popularity of the term "natural laboratory" shows the advantages scientists perceived in the capacity to combine the advantages of field and laboratory settings in the distinctive polar regions. As Oreskes (1999) notes in her chronicle of geology's transition from the 19th to the 20th century, the proponents of laboratory science emphasized the values of exactitude, precision, and control, while the field scientists promoted the values of authenticity, accuracy, and completeness. From Weyprecht to the IGY, organized international science in the Arctic has attempted to merge the values of the laboratory and the field. These combined values continue to surface in large-scale Arctic environmental studies such as the Surface Heat Budget of the Arctic (SHEBA), a coordinated international project to investigate the role of Arctic climate in global change (SHEBA Phase II Science Team, 1997), and in other projects that rely on year-round platforms in the Arctic.

The large-scale, synchronous observations from the IGY required equally large-scale data repositories and publication efforts, so IGY organizers established a set of World Data Centers to collect, manage, and store the volumes of information. In addition to embracing the values of field and laboratory science, the scientist members of the United States National Committee for the IGY were also concerned that the data generated by IGY be made available for immediate use. During World War II and in the immediate postwar period, meteorological and other atmospheric data were officially classified in the national interest. In the early 1950s, Cold War tensions between the East and West meant that a great deal of data continued to be classified and thus rendered unavailable for use in unclassified research. During the first meeting of the U.S. National Committee for the IGY in March 1953, the atmospheric and earth scientists at the table talked about the necessity of obtaining Russian data and of sharing U.S. data with the Russians. Sharing data with international partners - 67 countries participated in the IGY - was seen as a necessary step to planning and carrying out the work (U.S. National Academy of Sciences, 1953; see also Needell, 2000). Sharing data in science, seen as a reciprocal obligation among roughly equal partners and a contribution toward general knowledge, is not the same as translating scientific results into usable information for nonscientists.

From the first IPY to the present, scientists studying polar regions have contributed enormously to our knowledge of global processes. That knowledge, in turn, has made it safer to travel, hunt, and live in the North. Thus, hostility directed toward research done by nonlocals may seem quite surprising. However, the context for Native political action was very different from the scientists' 
conception of the Arctic as a key region to understand global processes in the atmosphere, land, and oceans.

\section{RESEARCH ETHICS IN THE NORTH}

World War II and the Cold War brought many indigenous populations of the North out of relative isolation into the spheres of national development and international conflict and cooperation. Border closings and relocations, disease epidemics, and dislocated communities and individuals are among the many tragedies of the wartime and East-West conflict (Coates, 1991; Tester and Kulchyski, 1994). In this period, science was often in service to the national interest; therefore, contacts with indigenous communities of the North tended to coincide with strategic site locations (e.g., the Distant Early Warning stations, highway and airfield construction). In some instances during World War II and the early Cold War, indigenous individuals participated in scientific studies as guides, research assistants, and lab technicians (Glenn and Sheehan, 1998; Arctic Research Consortium of the United States, 1999). In other cases, Native individuals were the unwitting subjects of medical experiments (National Research Council, 1996). At no point on the participation continuum, however, were Natives equal partners in science.

The political mobilization of indigenous peoples since the 1960s has changed the social and political landscape of the North. Quests for autonomy and recognition of rights led to land-claim demands, processes, and settlements and the formation of new self-government institutions (e.g., Korsmo, 1990; Cairns, 2000; Hicks and White, 2000).

As northern indigenous peoples brought forward claims on a national scale, they also brought up their frustrations concerning the activities of researchers. From the indigenous perspective, northern research could be used to support projects that might lead to drastic changes in the northern landscape and economy (Graham, 1999). The tremendous volume of research that preceded the Mackenzie Valley Pipeline Inquiry contributed to raising so much suspicion and resistance among the Mackenzie Valley communities that Justice Thomas Berger recommended a ten-year moratorium on the pipeline. That decade would, he believed, give time for land-claim settlements and greater aboriginal input into development and the research that supports it. In Canada, federal government officials, anthropologists, and other scientists responded to such concerns by raising the issue of researcher responsibility to consult with communities. For example, in 1976 the Department of Indian Affairs and Northern Development published a pamphlet entitled "Guidelines for Scientific Activities in Northern Canada," which called for prior consultation and informed agreement with northern communities. Graham (1999) notes that the government appeared to be motivated by the goal of improving the living standards in the North and saw the results of research contributing to that effort.
The Canadian Man and the Biosphere (MAB) project, a component of the larger UNESCO MAB project, also addressed the problem of researcher-community relations in a 1978 paper entitled "Ethical Principles for the Conduct of Research in the North." The MAB principles were drawn from social science research guidelines but were to apply to all scientific fields (Graham, 1999). MAB turned this discussion paper over for further development to the Association of Canadian Universities for Northern Studies (ACUNS), which had been founded at Churchill, Manitoba, in 1977 to advance northern scholarship through education, professional and scientific training, and research (ACUNS, 1998). ACUNS developed and published Ethical Principles for the Conduct of Research in the North (1982) to promote cooperation and mutual respect between researchers and the people of the North. To ensure that the principles would be accessible, the document was written in clear, readable language and published in English, French, and Inuktitut. The introduction to the 1982 edition of the ACUNS principles acknowledges that "researchers have worked in isolated communities without regard for the people who live there. Communities have been disrupted, and essential local resources used without consultation." Essentially, the ACUNS principles express social science guidelines concerning anonymity for human subjects, informed consent, respect for privacy and dignity, and the goal of sharing data and research benefits with the community (ACUNS, 1998).

The discussions in Canada set the stage for other research organizations to develop similar guidelines, for example the "Principles for the Conduct of Research in the Arctic," adopted by the U.S. Interagency Arctic Research Policy Committee (IARPC) (IARPC, 1990). The U.S. principles go one step beyond the ACUNS principles, in that they urge researchers to incorporate local and traditional knowledge into the research design. Both the ACUNS and the IARPC principles advocate translation of the research results into the local languages. Similarly, the International Arctic Social Sciences Association adopted ethical principles in 1998 (IASSA, 1998).

In 1995, ACUNS began revision of the 1982 Ethical Principles with the assistance of academics, government officials, scientists, Aboriginal organizations, and research organizations. The revisions, adopted in 1997 and published in 1998, reflect political and social changes in the Canadian North brought by land-claim settlements and self-government agreements. The revised principles call for community consultation at all stages of the research, including design and implementation and, where possible, for incorporation of local research needs into the research design and incorporation of relevant traditional knowledge into all stages of the research. The key word is partnership: researchers and community members are to be equal partners in the design and conduct of research.

While social and health researchers have concerned themselves with ethical conduct for some time, the northern research guidelines that emerged from ACUNS and 
IARPC are not confined to these disciplines. The ACUNS principles, both the 1982 and the 1998 versions, explicitly state that they are to apply to all science done in the North, although provisions to protect human subjects apply principally to social and medical research. Similarly, the U.S. principles of conduct, though drafted by an interagency social sciences task force, were adopted by federal agencies that sponsor research in various disciplines. The 1998 ACUNS document (ACUNS, 1998: 8) offers an exception for non-social science research:

\begin{abstract}
Some types of physical science or exploratory research might not appear to require the researcher to consider all the principles we've included here. This is a particularly important point. Research on physical phenomena at a distance from communities, trap lines, hunting territories, or traditional lands, might need nothing beyond the applicable permits. In other areas, the situation might require discussion of a project with a community. A researcher might not need to secure, for example, the informed consent of an individual as a participant or a subject in the research project. Nevertheless, the researcher might have to consider securing informed consent of an individual who might be a partner, a collaborator, or an informant, or of an individual or a community that might have to live with the effects of the research results or of its actual conduct (on community relations, game, land, water, etc.). [emphasis in original]
\end{abstract}

This statement reminds scientists that their research may have unintended consequences for local inhabitants. For example, a study of waterfowl population trends and breeding sites may reveal closely held information important to the people of a nearby community or generate results that distant authorities could use to change regulations, to the detriment of the local hunters. Studies have shown that heavy metals and persistent organic pollutants tend to be found in marine and other mammals and birds used as traditional foods by northern people (AMAP, 1998). When it comes to communicating the results of such studies, should scientists emphasize the health risks of relying on traditional foods? Or should they point out that nontraditional diets, with comparatively high proportions of carbohydrates, cause more health problems for Northerners who are used to living off the land and sea? Considering the possible effects of research (from both the ways in which it is carried out and its results) adds a new dimension to the biological and physical sciences.

The development of ethical principles and guidelines in Canada and the United States proceeded largely with the participation of social scientists. Complaints from the North arose from local perceptions that well-funded researchers were taking intellectual property and enhancing their careers at the expense of Northerners (Tizya, 1975; Flaherty, 1995). To continue to work as researchers, social scientists had to listen and respond to these concerns. More recently, however, indigenous organizations and governments have begun to develop their own guidelines and requirements for all scientific visitors. The next section explores this new development and its implications for field research.

\section{INSTITUTIONAL CHANGE AND NEGOTIATED RELATIONSHIPS}

As shown above, the revised ACUNS Ethical Principles of 1997 (ACUNS, 1998) emphasize partnerships between Northerners and researchers. While there are many possible reasons for this new emphasis, one could interpret this as a change of clients. Indeed, as self-government agreements have been put into place, indigenous residents themselves are taking a more active, regulatory role in research. In Canada, legal frameworks support this role. But as we shall see, the challenges in researcher-community relations involve more than a simple shift in power.

Throughout the 20th century, until the post-Cold War thaw, regulation of science and exploration in the North was motivated primarily by concern for establishing or defending the sovereignty and territorial claims of the nation-state. Governments, most often national ones, supported exploration and science at the frontier to strengthen or extend territorial claims, identify resources, improve commerce or local conditions, and achieve superior communications for national defense (e.g., Needell, 2000; Bamford, 2001). The situation has changed considerably in the last decade.

From the early 1970s, aboriginal land claims and their negotiations resulted in the formation of new organizations, governments, constitutional provisions, and management rules (e.g., Cairns, 2000; Hicks and White, 2000). In Canada, northern research was once the purview of the federal government, the universities, and various independent bodies such as the Arctic Institute of North America. Senkpiel and Easton (1988) see the expansion of northern research after the mid-1980s as the result of three parallel developments: devolution of authority from the federal government to the territorial governments, the rise of Native activism across the North, and the creation of two colleges north of the 60th parallel. Certainly the thinking that led the Government of the Northwest Territories (GNWT) to set up the framew ork for overseeing and licensing research under a statute called the NWT Scientists Act (Department of Justice of Canada, 1985 [1], c.4) was prompted by contemporary discussions about education and research in the North (Graham, 2000). Under the statute, the NWT Legislative Assembly established the Science Institute of the Northwest Territories (SINT) in 1984. SINT, operated at arm's length from government, was responsible for, among other things, operating the four federal research centers, encouraging science education, and licensing researchers (Greenaway, 1979). In 1995, in anticipation of the 1999 division of the territory, SINT was divided into a western and an eastern institute, 
which were then merged with Aurora College in the western Northwest Territories and with Nunavut Arctic College in the eastern Northwest Territories. The Aurora Research Institute (ARI) in Inuvik now handles licensing for the Northwest Territories, and the Nunavut Research Institute (NRI) in Iqaluit, for Nunavut (NRI, 1997; ARI, 1998). Both research institutes have focused their attention on the needs and concerns of their constituents and have acted as go-betweens for researchers and communities. In that capacity, they have conducted community consultations and developed research agendas and guides. In 1998, the Nunavut Research Institute and the Inuit Tapirisat of Canada published a pamphlet entitled "Negotiating Research Relationships: A Guide for Communities" (Nunavut Research Institute and Inuit Tapirisat of Canada, 1998). The pamphlet explains the rights of communities and community members to decide how research is done in their area, identifies ways communities can become involved, and offers guidelines for establishing partnerships with researchers. It does not address the rights of researchers or the obligations of the communities.

In the Yukon, arrangements differ because the government has not assigned research licensing to a Crown corporation. (The Yukon Science Institute, which might be imagined to be similar to the institutes in the NWT and Nunavut, is a membership organization formed to raise consciousness about science and science education among northern residents.) Instead, the Heritage Branch of the Yukon Government's Department of Tourism handles research licensing, although the final land-claim agreements acknowledge the First Nations' right to control access to their settlement lands and traditional territories. In contemporary practice, the Heritage Branch works cooperatively with Yukon First Nations. Upon receiving a research license application for work that might affect a First Nation or its lands, the branch consults with the First Nation. The First Nation may grant or refuse access to its settlement lands or traditional territories, or it might impose additional conditions or restrictions on the researcher or the research. For some types of research, more than one license may be required.

In Alaska, no one body or agency handles research permits; the arrangements depend on the nature of the research activity and the ownership and jurisdiction of the land. The Alaska Federation of Natives drew up ethical guidelines in 1993, and the Alaska Native Science Commission drafted a sample code of research ethics in the late 1990s, but neither document has official legal status (Alaska Federation of Natives, 1993; Alaska Native Science Commission, 2000). In contrast, research in Greenland must be approved by a Commission. Until recently, Greenlanders on what was then called the Commission for Scientific Research in Greenland comprised a minority, and Danes, the majority. The newly constituted Commission for Danish-Greenlandic Research Cooperation (KODAGS) places Greenland in a better position. The new Commission has 11 members rather than 18 . Greenland selects the chair and five members; Denmark, the other five members (Sejersen, 1999). In addition, the Greenland Home Rule Government is currently considering a draft of ethical research guidelines taken from the Greenlandic Parliament's discussions of 1994 and 1995 (Grønlands Hjemmestyre, 1997).

All of these developments point to an increasingly visible expression of indigenous peoples' desire to have more control over northern research and to share the benefits that accrue from such research. As the Nunavut Research Institute and Inuit Tapirisat of Canada's (1998:4-5) pamphlet, "Negotiating Research Relationships," explains:

\begin{abstract}
We wrote this guide because Inuit have the right to set priorities for research and to influence how research gets done; and because research has the potential to be very valuable both to researchers and the communities involved. Unfortunately, northern research has not always been helpful to everyone it affects. Researchers have been coming to Inuit communities for many years to study all kinds of things about Inuit life, culture and the environment. People in the communities have told us that they aren't always sure about what researchers do, why they do it and how their research benefits the community. Many Inuit feel they have not been involved enough in the research process.
\end{abstract}

The problem, then, is lack of involvement with and communication to members of indigenous communities. The solution to the problem, as contained in the various statements of ethical principles and the licensing requirements and guidelines of the Nunavut and Aurora Research Institutes, is negotiated collaborations. These statements emphasize establishing and maintaining relationships, a time-consuming and challenging task for parties whose aspirations and concerns differ as markedly as those of researchers and northern community members often do.

Negotiated relationships between natural or physical scientists (i.e., not only the social scientists) and indigenous communities do exist in the Arctic. For example, Canada's Northern Contaminants Program (NCP) is managed by a committee of federal agencies, territorial governments, and Inuit, Dene, Metis, and Yukon First Nations organizations (Watt-Cloutier, 2000). The Alaska Native Science Commission and the U.S. National Science Foundation (NSF) negotiated a cooperative agreement to help establish collaborations between Alaska Native villages and organizations and NSF-supported scientists. Concern about the environmental effects of contaminants, climate change, and ozone loss is shared by many people and easily translates into a common agenda for collaborative research. However, factors other than the topic of study, such as the locus of control, can make collaboration extremely challenging.

Questions of who controls and allocates the resources involved in scientific research are contentious in many different settings. But in the relationship between scientists and indigenous communities, differences in beliefs 
about science itself can be obstacles to communication or collaboration. The scientific research process is founded on some basic principles. First, the research should be conducted under as close as possible to controlled conditions. This is much easier in the laboratory than in the field. However, even data collection in the field should be well documented. Subsequent researchers must be able to replicate the experiment using the same methods and obtain the same results before a conclusion is accepted. Second, the research should be able to be generalized beyond an individual case to have broadly applicable value. Third, scientific research does not necessarily lead to practical applications or policy-relevant ends. "Pure" or "basic" research contributes to a general understanding of nature; it provides the means of answering a large number of practical questions, but it may not give a specific solution to any one of them (Bush, 1945; England, 1982). Thus, science training differs from that in law or medicine; doctors and lawyers solve problems in their specialties. If a science team begins with a pressing problem such as pollution, the burden is on the team to demonstrate its lack of bias in the conduct of the research. Shapin (1996:164) describes this as a great paradox in modern science: "The more a body of knowledge is understood to be objective and disinterested, the more valuable it is as a tool in moral and political action."

The idealized model of scientific inquiry certainly does not translate easily into practice. Science is often a messy business, driven by cultural, political, and personal motivations as much as by a quest for knowledge (e.g., Hevly, 1992; Kuklick and Kohler, 1996). However, the basic principles of replicability, generalizability, and objectivity are important rules of the game-characteristics that scientists use to describe their own work and images of themselves. For example, when social scientists sought access to U.S. National Science Foundation grant programs in the 1950s, they emphasized similar features ("objectivity, verifiability, and generality") that made their sciences congruent with natural and physical sciencesand thus highly qualified for funding as "basic" science (England, 1982:267).

Given the basic tenets of the scientific tradition, research communities may well have specific concerns about the notion of a community of Arctic residents controlling the conduct and results of research. Such concerns might include the following:

Intellectual merit and freedom: Highly trained professionals see their role as seeking answers to complex and difficult questions. If a nearby community does not share the interest in pursuing knowledge, then the community interests may be inimical to a science designed to serve a greater society.

Time: The need to negotiate and consult, a potentially time-consuming process, may impede careers of junior faculty, who need to publish sufficiently to be considered for tenure and promotion within four to seven years of their hiring.
Information: The pursuit of scientific knowledge of cause and effect hinges on open access to information. If a community wishes to suppress results from a study, then science has not been served.

Local vs. universal questions: If a community is to guide the research, including the framing of scientific questions, then its locally focused questions may trump the quest for more generalized knowledge.

Uncertainty as to what constitutes a community: Researchers often express their uncertainty about the proper authorities to consult. Who represents a community? Is it the village elders? The elected council? In the North, a complex layering of authorities and landowners leaves many people confused. Other areas of uncertainty involve fundamental questions applicable to any area: What constitutes adequate consultation? When are the obligations met? Indeed, what constitutes a single community when there are fluid boundaries of language, ethnicity, geography and history? (see, e.g., Agrawal and Gibson, 1999)

Establishment and enforcement of mutual obligations: If the researchers operate under a code of conduct, what code regulates community members' behavior toward researchers? What recourse do researchers have when they meet inappropriate advances or outright hostility?

These issues are not unique to the Arctic, but rather permeate the "ecology" of the science-society relationship, as outlined by Byerly and Pielke (1995). Byerly and Pielke contend that the post-World War II relationship between science and society, as set forth by Bush (1945), isolated scientific research from societal problems. Now that the Cold War is over, according to the authors, there needs to be a broad discussion involving both scientists and nonscientists in an attempt to renegotiate a social contract that would give science "a more robust and responsive relation with its environment" (Byerly and Pielke, 1995:1532). The questions and concerns listed above are surfacing as a result of these discussions. In two areas of science-society relationships-genetic research and environmental management-researchers are seeking accommodations with groups of people who are directly affected by research.

Genetic research on human populations, both modern and ancient, gives rise to ethical questions. These involve community and individual consent; risk/benefit calculations for the groups involved, as well as for the larger society; and appropriate methods to involve, educate, and inform the people most likely to be affected by the results of the research. For example, when a specific population group has a higher frequency of a particular genetic variant that contributes to a disease, studying the variant in the specific group can help to identify the variant. It can also result in stigmatization of the group. The challenge is to balance the potential medical benefits with the potential risks (Collins, 2000).

To study ancient DNA and human history, researchers must obtain consent from indigenous communities for access to skeletal remains. This can be difficult if the 
modern communities are engaged in political or legal conflicts over resources, tribal authority, or other contentious issues that touch upon the identity and status of the community. On the other hand, some indigenous communities work willingly with physical anthropologists and genetic researchers to learn more about their history. As O'Rourke et al. (2001) noted in a presentation to the American Association of Physical Anthropology, there is no single model of community consultation that will be uniformly effective for all researchers: "Our recent experience is that communities increasingly take the lead in developing such consultation procedures, and we ignore them at our peril."

In environmental and natural resource management, community consultation has become a requirement for international lenders to developing countries, such as the World Bank and the Global Environmental Facility. The underlying assumption is that the principles of openness, accountability, and a plurality of vocal and engaged interest groups contribute to the goal of environmental protection (see e.g., Payne, 1998). Critical factors in effective public participation include local capacity to organize and represent the interests of individuals; government commitment to participatory methods; decentralization of administration; education, public awareness, and local commitment; and availability of resources and training to empower affected populations as participants and managers (Rosenberg and Korsmo, 2001). Although development projects generally do not constitute research, the tasks involved in determining the environmental impacts of dams, waste treatment facilities, and other installations include scientific research. Community involvement in the research not only broadens the database that can be used in decision making, but also helps to prevent the perception that outside "experts" are dictating a course of action.

There is no single way to overcome the challenges of collaborative science-society relationships. Much depends on the local political and social climate, the past experiences of communities with research and researchers, and the willingness of research proponents to overcome the challenges. Given the variety of conditions, a single legislated or recommended approach to negotiating satisfactory collaboration is unlikely. One possibility is to employ a broker, either an individual or an organization. Caution, however, must be exercised because brokers can be harmful when they misrepresent one group to another. A good broker is an interpreter conversant in at least two different languages or cultures and motivated to provide assistance to more than one group rather than just a single group. A cultural anthropologist, an educator, a community leader, or a student can fill the role of an individual broker. Institutions such as the Aurora Research Institute, the Nunavut Research Institute, northern universities, and indigenous organizations can also provide assistance.

An intermediate form of brokering relationships is setting up formal, explicit ties between researchers and indigenous communities, in the form of advisory committees, memoranda of understanding, science steering committees, and other consultative processes and fora. However, at least one researcher has warned that such forms of institutionalized consultation-in this case the incorporation of traditional ecological knowledge in resource management-can increase bureaucratization and concentrate power in administrative centers rather than in the local communities (Nadasdy, 1999). Nevertheless, if the formal mechanism is geared toward easing the ongoing transmission of information between parties, rather than toward one-time collection of data, the arrangements can be mutually beneficial. Establishing such mechanisms for consultation does increase the time needed for research and points to the need for long-standing financial commitments.

Yet another way to encourage negotiations is to adjust the reward structures for scientists, allowing them time to consult with indigenous communities as necessary. Granting organizations or universities could provide travel grants to researchers, particularly students and junior faculty, who wish to present preliminary research ideas to northern communities and to listen to their reactions and suggestions. Travel grants to researchers inevitably raise the issue of other kinds of funding; indigenous communities are justified in the request that expert hunters, fishers, and elders be compensated for their time as participants in a research project. Again, this issue requires careful negotiation between the science team and the community, as well as a more generous understanding of research costs on the part of funding organizations.

\section{DISCUSSION AND CONCLUSION}

Over the last two decades, the changed nature of institutions in the North, particularly in northern Canada and the United States, has resulted in new guidelines for research conduct. Whether the guidelines come directly from nongovernmental organizations or from federal, territorial, or local authorities, they all call for increased collaboration with indigenous communities.

In this paper, we have reviewed the various guidelines, pointed out philosophical differences between scientific traditions and the community-based approach, and suggested possible means of pursuing collaborations without compromising scientific methods.

This is not the first time that institutional change and instability have led to questions about the nature of science and scientific authority. The religious wars between the Catholics and the Protestants of the 17th century influenced views of knowledge and its role in maintaining or disrupting social order (Shapin, 1996). In a similar manner, the current turn toward traditional ecological knowledge (TEK) as an alternative knowledge system to Western science has come to the fore in the wake of northern indigenous peoples' challenges to the political and legal order (Usher, 2000). This trend has also been met with skepticism. In the Arctic, as in other parts of the world, a 
debate centers on the legitimacy of knowledge and scientific method, which is intimately tied to questions of power.

Social, physical, and natural scientists are now participating in the debate and openly discussing the challenges of collaboration. For example, an interdisciplinary research team collaborated with four northern communities to examine how the combined effects of climate change, oil development, tourism, and government cutbacks might alter the sustainability of Arctic villages. Considerable tension resulted when it became clear that the communities and the researchers had different priorities. However, according to the participants, they reached a compromise that changed the scope of the study, at least initially (Kruse et al., 2000). Was the science compromised by the decision? According to the authors, sound science and local knowledge can coexist, but it takes extensive negotiations (Kruse et al., 2000).

The scientists planning the International Geophysical Year operated under a different set of tensions: Cold War competition. Some of them worked for national security agencies and understood well the place of knowledge in world order (Needell, 2000). Others, impressed by the openness of international IGY collaboration between East and West, were surprised by the extent of technological warfare conducted in secret. In both cases, value was placed on science as an objective, disinterested entity capable of informing the answers to moral and political questions.

Science-society relationships in the North continue to form and reform in very different political, legal, and social settings. Indigenous societies and governments are formulating their aspirations for scientific conduct. Some of the topics, such as intellectual property, directly challenge the ideals of data sharing and peer review, just as data classification and military secrecy challenged the organizers of the IGY. As we have seen from the fields of genetic research and environmental management, however, there are ethical reasons and practical means for respecting the wishes of indigenous communities and negotiating a collaborative relationship.

\section{ACKNOWLEDGEMENTS}

The authors would like to thank the people who read earlier versions of the manuscript, including the anonymous reviewers. An earlier version of the paper was presented at the biennial conference of the Association for Canadian Studies in the United States held in Pittsburgh on 17-21 November 1999. Please note that this article reflects the views of the authors and does not represent the official policies or positions of the National Science Foundation or the Office of Polar Programs.

\section{REFERENCES}

ACUNS (ASSOCIATION OF CANADIAN UNIVERSITIES FOR NORTHERN STUDIES). 1998. Ethical principles for the conduct of research in the North. Ottawa: Association of Canadian Universities for Northern Studies.

AGRAWAL, A., and GIBSON, C.C. 1999. Enchantment and disenchantment: The role of community in natural resource conservation. World Development 27(4):629-649.

ALASKA FEDERATION OF NATIVES. 1993. Guidelines for research. <http://www.ankn.uaf.edu/afnguide.html>. Accessed 31 July 2002.

ALASKA NATIVE SCIENCE COMMISSION. 2000. Sample code of research ethics. <http://www.nativescience.org/html/ Code $\% 20$ of $\% 20$ Research\%20Ethics.html>. Accessed 31 July 2002.

AMAP (ARCTIC MONITORING AND ASSESSMENT PROGRAM). 1998. Assessment report: Arctic pollution issues. Oslo: AMAP.

ARCTIC RESEARCH CONSORTIUM OF THE UNITED STATES. 1999. Future of an Arctic resource: Recommendations from the Barrow area research support workshop. Fairbanks: Arctic Research Consortium of the United States.

ARI (AURORA RESEARCH INSTITUTE). 1998. Doing research in the Northwest Territories: A guide for researchers. Inuvik: ARI.

BAMFORD, J. 2001. Body of secrets: Anatomy of the ultra-secret National Security Agency from the Cold War through the dawn of a new century. New York: Doubleday.

BARR, W. 1983. Geographical aspects of the First International Polar Year, 1882-1883. Annals of the Association of American Geographers 73(4):463-484.

BUSH, V. 1945. Science: The endless frontier. In: National Science Foundation, 40th anniversary, 1950-1990. Washington, D.C.: National Science Foundation.

BYERLY, R., Jr., and PIELKE, R.A., Jr. 1995. The changing ecology of United States science. Science 269 (15 September): $1531-1532$.

CAIRNS, A.C. 2000. Citizens plus: Aboriginal peoples and the Canadian state. Vancouver: University of British Columbia Press.

CHAPMAN, S. 1960. From Polar Years to Geophysical Year. Studia Geophysica et Geodetica 4(4):313-324.

COATES, K.S. 1991. "Best left as Indians:" Native-white relations in the Yukon Territory, 1840-1973. Montreal, Kingston: McGillQueen's University Press.

COLLINS, F. 2000. The culture of science: The biomedical outcomes of genome research. In: Greenberg, J., ed. Report of the first community consultation on the responsible collection and use of samples for genetic research, 25-26 September. Bethesda, Maryland: National Institute of General Medical Sciences, National Institutes of Health. <http://www.nigms.nih.gov/news/ reports/community_consultation.html >. Last updated 3 January 2001.

CURRIE, B.W. 1987. The Second International Polar Year, $1932-$ 33: Canadian participation. Musk-ox 35:3-6.

DEPARTMENT OF JUSTICE OF CANADA. 1988. Statutes and Regulations of the Northwest Territories, Scientists Act, R.S.N.W.T. 1988. c. S-4. <http://www.lex-nt.ca/>

ENGLAND, J.M. 1982. A patron for pure science: The National Science Foundation's formative years, 1945-1957. Washington, D.C.: National Science Foundation. 
FLAHERTY, M. 1995. Freedom of expression or freedom of exploitation? Northern Review 14 (Summer):178-185.

GERSON, N.C. 1958. From Polar Years to IGY. In: Landsberg, H.E., and Van Mieghem, J., eds. Advances in geophysics. New York: Academic Press. 1-52.

GLENN, R., and SHEEHAN, G. 1998. Arctic science: A brief overview of the Barrow Arctic Consortium, the Barrow Environmental Observatory and related research activities at Barrow, Alaska. Barrow: Barrow Arctic Science Consortium.

GRAHAM, A. 1999. Communicating across cultures in the Canadian North: Research, researchers, northerners and ethics. Draft paper prepared for June 1998 Communicating Across Cultures Conference, Western Washington University, Bellingham, WA. . 2000. The university that wasn't: The University of Canada North, 1970-1985. M.A. Thesis, Lakehead University, Department of History, 1994. PDF Version <http:// www.yukoncollege.yk.ca/ agraham/papers/ucn.pdf > Accessed on 31 July 2002.

GREENAWAY, K. 1979. A framework for scientific activities in the Yukon and Northwest Territories. Unpubl. discussion paper, 11 April. Available from Indian and Northern Affairs Canada, Terrasses de la Chaudière, 10 Wellington, North Tower, Hull, Quebec; Postal address: Ottawa, Ontario K1A 0H4.

GRØNLANDS HJEMMESTYRE. 1997. Forskningspolitisk redegørelse og handlingsplan, 1998-2000. INUSSUK: Arktisk forskningsjournal. Nuuk: Direktoratet for Sundhed og Forskning.

HEVLY, B. 1992. Reflections on big science and big history. In: Galison, P., and Hevly, B., eds. Big science: The growth of large-scale research. Stanford: Stanford University Press. $355-363$.

HICKS, J., and WHITE, G. 2000. Nunavut: Inuit self-determination through a land claim and public government? In: Dahl, J., Hicks, J., and Jull, P., eds. Inuit regain control over their lands and their lives. Copenhagen: International Work Group for Indigenous Affairs. 30-116.

IARPC (INTERAGENCY ARCTIC RESEARCH POLICY COMMITTEE). 1990. Principles for the conduct of research in the Arctic. <http://www.nsf.gov/od/opp/arctic/conduct.htm>.

IASSA (INTERNATIONAL ARCTIC SOCIAL SCIENCES ASSOCIATION). 1998. Minutes from the last IASSA General Assembly. IASSA Newsletter (Fall):1-2. See also <http:// www.uaf.edu/anthro/iassa/newsf98.html>

KORSMO, F.L. 1990. Problem definition and the Alaska Natives: Identity and policy formation. Policy Studies Review 9(2): 294-306.

KRUSE, J. et al. 2000. Sustainability of Arctic communities: An interdisciplinary collaboration of researchers and local knowledge holders.<http://www.taiga.net/sustain/lib/reports/overview. pdf>

KUKLICK, H., and KOHLER, R.E. 1996. Introduction. In: Kuklick, H., and Kohler, R.E., eds. Science in the field. Osiris 11:1-14.

LEVERE, T.H. 1993. Science and the Canadian Arctic: A century of exploration, 1818-1918. Cambridge: Cambridge University Press.

NADASDY, P. 1999. The politics of TEK: Power and the "integration" of knowledge. Arctic Anthropology 36:1-18.
NATIONAL RESEARCH COUNCIL, Committee on Evaluation of 1950s Air Force Human Health Testing in Alaska using Iodine-131. 1996. The Arctic Aeromedical Laboratory's thyroid function study: A radiological risk and ethical analysis. Washington, D.C.: National Academy Press.

NEEDELL, A.A. 2000. Science, Cold War, and the American state. Washington, D.C.: Harwood Academic Publishers and the Smithsonian Institution.

NRI (NUNAVUT RESEARCH INSTITUTE). 1997. Nunavut research agenda: Research policy and needs for Nunavut. Available from Nunavut Research Institute, P.O. Box 1720, Iqaluit, Nunavut. <http://pooka.nunanet.com/ research/>

NUNAVUT RESEARCH INSTITUTE and INUIT TAPIRISAT OF CANADA. 1998. Negotiating research relationships: A guide for communities. Ottawa: Inuit Tapirisat of Canada.

ORESKES, N. 1999. The rejection of continental drift: Theory and method in American earth science. Oxford: Oxford University Press.

O'ROURKE, D.H., HAYES, M.G., and CARLYLE, S.W. 2001. The consent process and aDNA research: Contrasting approaches in North America. Presentation at the session on biological anthropology and ethics, American Association of Physical Anthropology, 26-28 March, Kansas City, Missouri.

PAYNE, R.A. 1998. The limits and promise of environmental conflict prevention: The case of the GEF. Journal of Peace Research 35(3):363-380.

ROSENBERG, J., and KORSMO, F.L. 2001. Local participation, international politics, and the environment. Journal of Environmental Management 62(3):283-300.

SEJERSEN, F. 1999. Research in Greenland-a Danish perspective. International Arctic Social Sciences Association (IASSA) Newsletter, Summer: 1. <http://www.uaf.edu/anthro/iassa/ newss99.html>

SENKPIEL, A., and EASTON, N.A. 1988. New bearings on northern scholarship. The Northern Review 1 (Summer):9-26.

SHAPIN, S. 1996. The scientific revolution. Chicago: University of Chicago Press.

SHEBA PHASE II SCIENCE TEAM. 1997. SHEBA Implementation Plan. Seattle: University of Washington. <http:/ /psc.apl.washington.edu/SHEBA/impl_plan/impl_plan_v2.pdf $\rangle$ Accessed 31 July 2002.

SULLIVAN, W. 1961. Assault on the Unknown. New York: McGraw-Hill.

TESTER, F.J., and KULCHYSKI, P. 1994. Tammarniit (Mistakes): Inuit relocation in the Eastern Arctic, 1939-63. Vancouver: University of British Columbia Press.

TIZYA, R.J. 1975. Special lecture: Research in the North as viewed by the communities. Proceedings of the Circumpolar Conference on Northern Ecology, September 15-18, Ottawa. Ottawa: National Research Council of Canada, Canadian National Committee, and Scientific Committee on Problems of the Environment.

U.S. ARCTIC RESEARCH PLAN. 1997. Biennial revision, 1998 2000. Arctic Research Journal of the United States 11 (Fall/ Winter).

U.S. NATIONAL ACADEMY OF SCIENCES, NATIONAL RESEARCH COUNCIL. 1953. U.S. National Committee, 
International Geophysical Year, Minutes, First Meeting, March 1953. Washington, D.C.: National Academy of Sciences IGY Archive.

USHER, P.J. 2000. Traditional ecological knowledge in environmental assessment and management. Arctic 53(2): $183-193$.
WATT-CLOUTIER, S. 2000. Keynote address to the 12th Inuit Studies Conference at the University of Aberdeen, Scotland. 23 August. Inuit Circumpolar Conference. <http:// www.inuitcircumpolar.com/index_of_Speeches/ index_of_Speeches.html>

ZELLER, S. 1996. Land of promise: The culture of Victorian science in Canada. Historical Booklet 56. Ottawa: The Canadian Historical Association. 